\title{
The gamma Burr XII distributions: Theory and applications
}

\author{
Renata Rojas Guerra $^{\text {a }}$, Fernando A. Peña-Ramírez ${ }^{\mathrm{a}}$ and Gauss M. Cordeiro ${ }^{\mathrm{a}}$ \\ ${ }^{a}$ Department of Statistics, Federal University of Pernambuco - Brazil
}

\begin{abstract}
We introduce a four-parameter distribution, called the Zografos-Balakrishnan Burr XII distribution. Our purpose is to provide a Burr XII generalization that may be useful to still more complex situations. The new distribution may be an interesting alternative to describe income distributions and can also be applied in actuarial science, finance, bioscience, telecommunications and modelling lifetime data, for example. It contains as special models some well-known distributions, such as the log-logistic, Weibull, Lomax and Burr XII distributions, among others. Some of its structural properties are investigated. The method of maximum likelihood is used for estimating the model parameters and a simulation study is conducted. We provide two application to real data to demonstrate the usefulness of the proposed distribution. Since the Ristić-Balakrishnan Burr XII distribution has a similar structure to the studied distribution, we also present some of its properties and expansions.
\end{abstract}

Key words: Burr XII distribution, gamma Burr XII distributions, gamma-G family, maximum likelihood.

\section{Introduction}

The Burr XII (BXII) distribution first appears as part of the Burr system of distributions. This system was introduced in 1942 by Irving W. Burr and comprises twelve distributions which yield a variety of density shapes, see Burr (1942). In the economic context, the BXII distribution is known under the name of Singh-Maddala, see Singh and Maddala $(1975,1976)$. Since then, it has received special attention in the literature of income distributions.

Several studies have been conducted considering the BXII distribution for modelling personal or family incomes in different countries, such as Czech Republic (Brzeziski, 2013), Hungary (Brzeziski, 2013), Pakistan (Shakeel et al., 2015), Poland (Brzeziski, 2013), Slovak Republic (Brzeziski, 2013), United Kingdom (Henniger and Schmitz, 1989; Jäntti and Jenkins, 2010) and United States (Majumder and Chakravarty, 1990; McDonald and Xu, 1995; Łukasiewicz et al., 2010; Tanak et al., 2015). Brzeziski (2014) also suggested that the BXII distribution is useful for empirical modelling of the distribution of journal impact factors. Jones et al. (2014) applied it to modelling inpatient cost in English hospitals.

\footnotetext{
${ }^{*}$ Corresponding author. Email: renata.rojasg@gmail.com
} 
The three-parameter BXII distribution (Zimmer et al., 1998) has cumulative distribution function (cdf) and probability density function (pdf) (for $x>0$ ) given by

$$
G(x ; s, d, c)=1-\left[1+\left(\frac{x}{s}\right)^{c}\right]^{-d}
$$

and

$$
g(x ; s, d, c)=c d s^{-c} x^{c-1}\left[1+\left(\frac{x}{s}\right)^{c}\right]^{-d-1},
$$

respectively, where $d>0$ and $c>0$ are shape parameters and $s>0$ is a scale parameter. If $c>1$, the density function is unimodal with mode at $x=s[(c-1) /(c d+1)]^{1 / c}$ and is L-shaped if $c=1$. If $c d>q$, the $q$ th moment about zero is $\mu_{q}^{\prime}=s^{q} d B\left(d-q c^{-1}, 1+q c^{-1}\right)$, where $B(a, b)=\Gamma(a) \Gamma(b) / \Gamma(a+b)$ is the beta function. Shao (2004) and Shao et al. (2004) studied the maximum likelihood estimation and the models for extremes for the three-parameter BXII distribution, respectively. Wu et al. (2007) discussed the estimation problems using this distribution based on progressive type II censoring with random removals. Silva et al. (2008) proposed a location-scale regression model based on this distribution.

Motivated by the extensive usage of the BXII distribution, some generalizations were proposed such as the beta Burr XII (Paranaíba et al., 2011) (BBXII) and Kumaraswamy Burr XII (Paranaíba et al., 2013) (KwBXII) distributions. We also refer the reader to the exponentiated Burr XII (Al-Hussaini and Hussein, 2011) (exp-BXII), Marshal-Olkin extended Burr XII (Al-Saiari et al., 2014; Kumar, 2016) and McDonald Burr XII (Gomes et al., 2015) distributions, among others. These distributions are obtained through different generalized (or generated) $\mathrm{G}$ families of continuous univariate distributions.

Another important class of univariate distributions is the gamma generalized family, called the gamma- $G$ class. Zografos and Balakrishnan (2009) proposed the first type gamma- $G$ family (ZB-G for short). They defined the ZB-G family with pdf $f(x)$ and cdf $F(x)$ given by

$$
f(x)=\frac{g(x)}{\Gamma(a)}\{-\log [1-G(x)]\}^{a-1},
$$

and

$$
F(x)=\frac{\gamma(a,-\log [1-G(x)])}{\Gamma(a)},
$$

respectively, where $G(x)$ is any baseline cdf, $g(x)=\mathrm{d} G(x) / \mathrm{d} x, x \in \mathbb{R}, \gamma(a, z)=\int_{0}^{z} t^{a-1} \mathrm{e}^{-t} \mathrm{~d} t$ is the incomplete gamma function, $\Gamma$ (.) denotes the gamma function and $a>0$ is a shape parameter. A different type gamma-G family was introduced by Ristić and Balakrishnan (2012), so-called the Ristić-Balakrishnan-G (RB-G) family, having pdf and cdf given by

$$
f(x)=\frac{g(x)}{\Gamma(a)}\{-\log [G(x)]\}^{a-1},
$$

and

$$
F(x)=1-\frac{\gamma(a,-\log [G(x)])}{\Gamma(a)},
$$


respectively. The ZB-G and RB-G families have the same parameters of the baseline $\operatorname{cdf} G(x)$ plus an additional shape parameter $a>0$. After a best possible search it was found that 18 distributions have been studied as baselines in the gamma- $G$ families. The list of authors' contributions is presented in Table 1.

Table 1: Contributed works on the Gamma-G families

\begin{tabular}{|c|c|}
\hline Distribution & Author \\
\hline Gamma exponentiated exponential & Ristić and Balakrishnan (2012) \\
\hline \multirow[t]{2}{*}{ Gamma Exponentiated Weibull } & Pinho et al. (2012) \\
\hline & Castellares and Lemonte (2015) \\
\hline Gamma Pareto & Alzaatreh et al. (2012) \\
\hline Gamma uniform & Torabi and Hedesh (2012) \\
\hline Gamma extended Fréchet & Silva et al. (2013) \\
\hline Gamma half normal & Alzaatreh and Knight (2013) \\
\hline Gamma Dagum & Oluyede et al. (2013) \\
\hline Gamma log-logistic & Ramos et al. (2013) \\
\hline Gamma Extended Weibull & Nascimento et al. (2014) \\
\hline Gamma linear failure rate & Cordeiro et al. (2014) \\
\hline Gamma logistic & Alzaatreh et al. (2014b) \\
\hline \multirow[t]{2}{*}{ Gamma normal } & Alzaatreh et al. (2014a) \\
\hline & Lima et al. (2015) \\
\hline Gamma Weibull Poisson & Percontini et al. (2014) \\
\hline Gamma Birnbaum Saunders & Cordeiro et al. (2015b) \\
\hline Gamma Lindley & Lima $(2015)$ \\
\hline Gamma Lomax & Cordeiro et al. (2015c) \\
\hline Gamma Modified Weibull & Cordeiro et al. (2015a) \\
\hline \multirow[t]{2}{*}{ Gamma Nadarajah Haghighi } & Bourguignon et al. (2015) \\
\hline & Ortega et al. (2015) \\
\hline
\end{tabular}

Following Zografos and Balakrishnan (2009) and Ristić and Balakrishnan (2012) proposals, we introduce a new four-parameter distribution called the Zografos-Balakrishnan Burr XII (ZBXII) distribution. Our purpose is to provide a BXII generalization that may be useful to still more complex situations. For example, Pareto suggested that income distribution follows a power law for those with high income (Pareto, 1987). However, subsequent studies found that this conjecture applies only to a small percentage of the population (Guo and Gao, 2012). Therefore, the characterization and understanding of the income distribution for the remaining majority of the population is still an open problem (Moura Jr and Ribeiro, 2009). Once the proposed distribution is quite flexible regarding pdf and hazard rate function (hrf), it may provide an interesting alternative to describe income distributions and can also be 
applied in actuarial science, finance, bioscience, telecommunications and modelling lifetime data, for example.

Zografos and Balakrishnan (2009) presented several motivations for the gamma-G family, which are also valid for the ZBXII distribution: if $X_{L(1)}, \ldots, X_{L(n)}$ are lower record values from a sequence of independent random variables with common $\operatorname{pdf} g(\cdot)$, then the pdf of the $n$th lower record value has the form (2); if $Z$ is a gamma random variable with unit scale parameter and shape parameter $a>0$ then $X=F^{-1}(\exp (Z))$ has the pdf (2); and, if $Z$ is a log-gamma random variable then $X=F^{-1}(\exp \{-\exp (Z)\})$ has the pdf $(2)$.

Since the RB-G family's cdf and pdf have a similar structure to the ZB-G family, we also present some mathematical properties and expansions for the so-called Ristić-Balakrishnan Burr XII (RBXII) model. These results follow analogously to those of the ZBXII distribution but with different weights in their linear representations (see Section 3).

Castellares and Lemonte (2016) also pointed out the relationship between the ZB-G and RB-G families by discussing some similarities and differences between the gamma dual Weibull model and gamma exponentiated Weibull model. The authors also proved that if the baseline $G(x)$ is absolutely continuous and symmetric about the origin, then $X$ follows the ZB-G distribution and $-X$ has the RB-G distribution. Unfortunately, this is not the case of the BXII distribution.

The paper is outlined as follows. In Section 2, we define the gamma BXII distributions and present some special models. In Section 3, we derive useful expansions for the pdf and cdf of the ZBXII distribution. A range of its mathematical properties is derived in Sections 4-6. The maximum likelihood estimation is used to estimate the model parameters in Section 7. In Section 8, a simulation study is conducted. Section 9 provides two applications to a real data sets. Section 10 gives some dual properties and useful expansions for the RBXII distribution. Finally, Section 11 presents concluding remarks.

\section{Models definition}

The gamma-G Burr XII distributions are defined be taking $G(x)$ in (2) and (3) to be the cdf (1) of the BXII distribution. These distributions contain as special models several well-known distributions. The BXII distribution is a special case for $a=1$. For $s=m^{-1}$ and $d=1$, they reduce to the gamma log-logistic distribution (Ramos et al., 2013). For $a=1$, $s=m^{-1}$ and $d=1$, they become the log-logistic (LL) distribution. If $d \rightarrow \infty$, they are identical to the gamma Weibull distribution. If $d \rightarrow \infty$ in addition to $a=1$, they become the Weibull distribution. For $c=1$ and $a=c=1$, they are equal to the gamma Lomax (Cordeiro et al., 2015c) and Lomax distributions, respectively.

\subsection{The ZBXII distribution}


The ZBXII distribution has cdf and pdf given by

$$
F(x)=\frac{\gamma\left(a, d \log \left[1+\left(\frac{x}{s}\right)^{c}\right]\right)}{\Gamma(a)}
$$

and

$$
f(x)=\frac{c d^{a} x^{c-1}}{s^{c} \Gamma(a)}\left[1+\left(\frac{x}{s}\right)^{c}\right]^{-d-1}\left\{\log \left[1+\left(\frac{x}{s}\right)^{c}\right]\right\}^{a-1},
$$

respectively, where $a>0, d>0$ and $c>0$ are shape parameters and $s>0$ is a scale parameter. If $X$ is a random variable with density function (5), we write $X \sim \operatorname{ZBXII}(a, s, d, c)$. The ZBXII hrf is given by

$$
h(x)=\frac{c d^{a} x^{c-1}}{s^{c} \Gamma\left(a, d \log \left[1+\left(\frac{x}{s}\right)^{c}\right]\right)}\left[1+\left(\frac{x}{s}\right)^{c}\right]^{-d-1}\left\{\log \left[1+\left(\frac{x}{s}\right)^{c}\right]\right\}^{a-1},
$$

where $\Gamma(a, z)=\Gamma(a)-\gamma(a, z)=\int_{z}^{\infty} t^{a-1} \mathrm{e}^{-t} \mathrm{~d} t$ is the upper incomplete gamma function.

Figure 1 reveals the versatility of the proposed density for some parameter values. The ZBXII pdf can take various forms, including power-law tails. This kind of tail is very common in economical systems and a important characteristic in income distributions. Figure 2 displays plots of the hrf for some parameter values. It reveals that the ZBXII distribution can have decreasing, decreasing-increasing-decreasing and upside-down bathtub hazard functions. This feature reveals that the ZBXII distribution is quite competitive with the BBXII model, which has the same forms for the hrf but one additional shape parameter.

\subsection{The RBXII distribution}

The RBXII distribution has cdf and pdf given by

$$
F(x)=1-\frac{\gamma\left(a,-\log \left\{1-\left[1+\left(\frac{x}{s}\right)^{c}\right]^{-d}\right\}\right)}{\Gamma(a)}
$$

and

$$
f(x)=\frac{c d x^{c-1}}{s^{c} \Gamma(a)}\left[1+\left(\frac{x}{s}\right)^{c}\right]^{-d-1}\left\{-\log \left(1-\left[1+\left(\frac{x}{s}\right)^{c}\right]^{-d}\right)\right\}^{a-1},
$$

respectively, where $a>0, d>0$ and $c>0$ are shape parameters and $s>0$ is a scale parameter. The RBXII hrf is given by

$$
h(x)=\frac{c d x^{c-1}\left[1+\left(\frac{x}{s}\right)^{c}\right]^{-d-1}}{s^{c} \gamma\left(a,-\log \left\{1-\left[1+(x / s)^{c}\right]^{-d}\right\}\right)}\left\{-\log \left(1-\left[1+\left(\frac{x}{s}\right)^{c}\right]^{-d}\right)\right\}^{a-1} .
$$

If $Y$ is a random variable with density function (7), we write $Y \sim \operatorname{RBXII}(a, s, d, c)$. Figures 3 and 4 display plots of the pdf and hrf for some parameter values, respectively. Note that this 


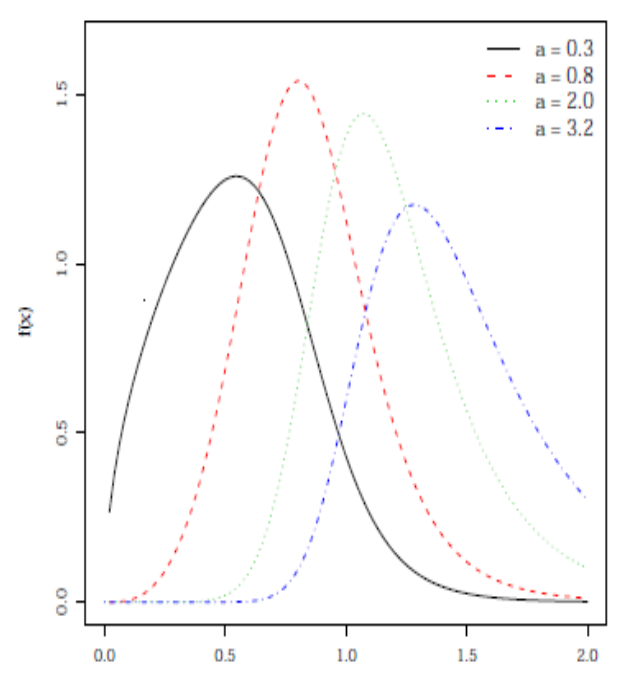

(a) For $d=1.5$ and $c=5.0$

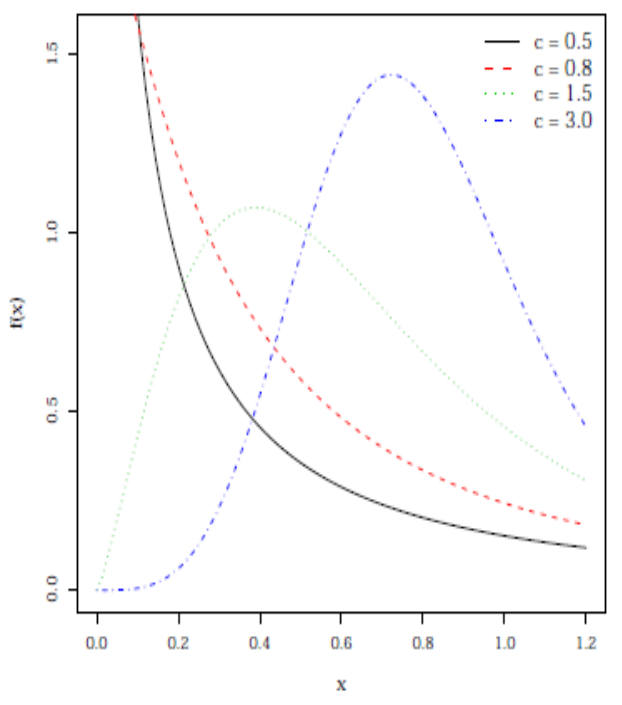

(b) For $a=1.5$ and $d=3.0$

Figure 1: Pdf plots for the ZBXII model with $s=1$

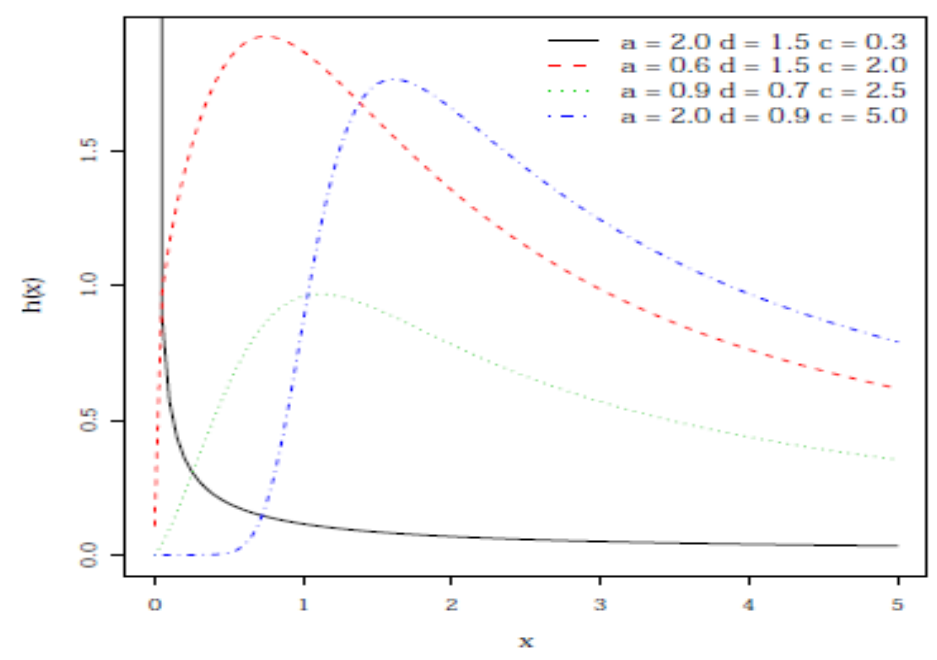

(a)

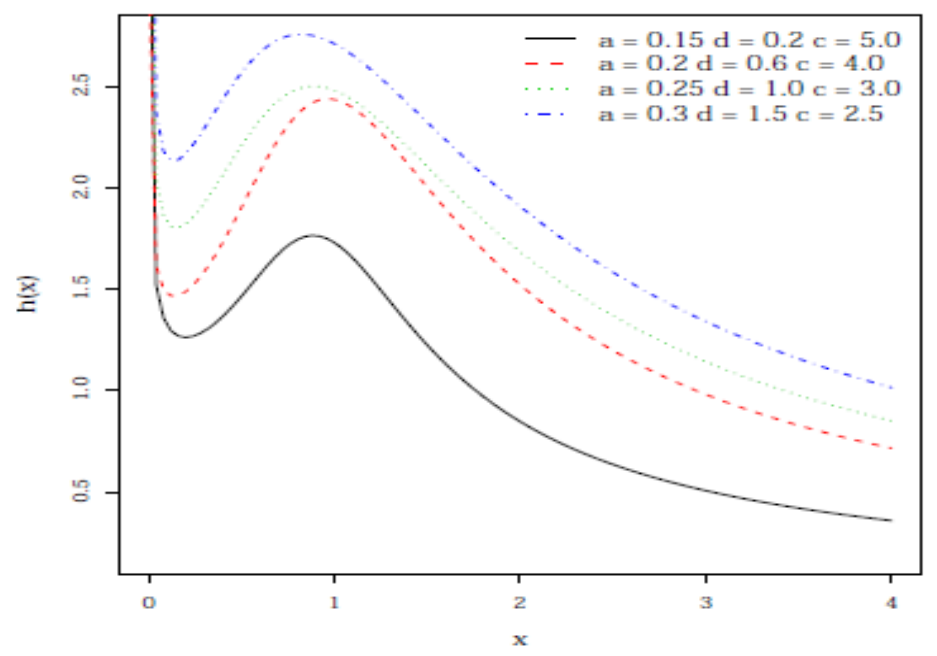

(b)

Figure 2: Hrf plots for the ZBXII model 


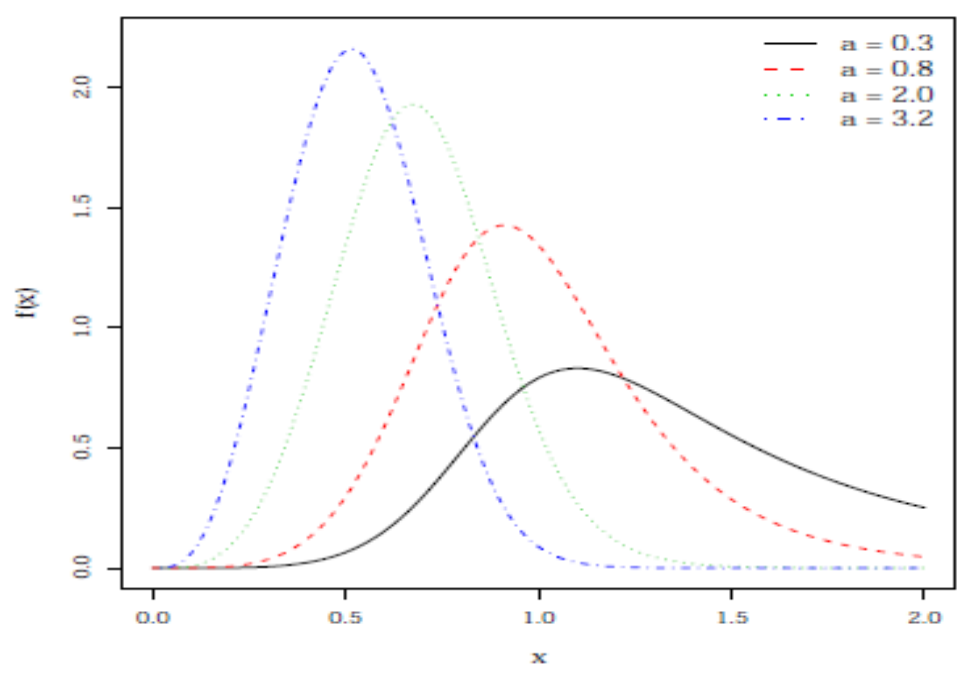

(a) For $d=1.5$ and $c=5$

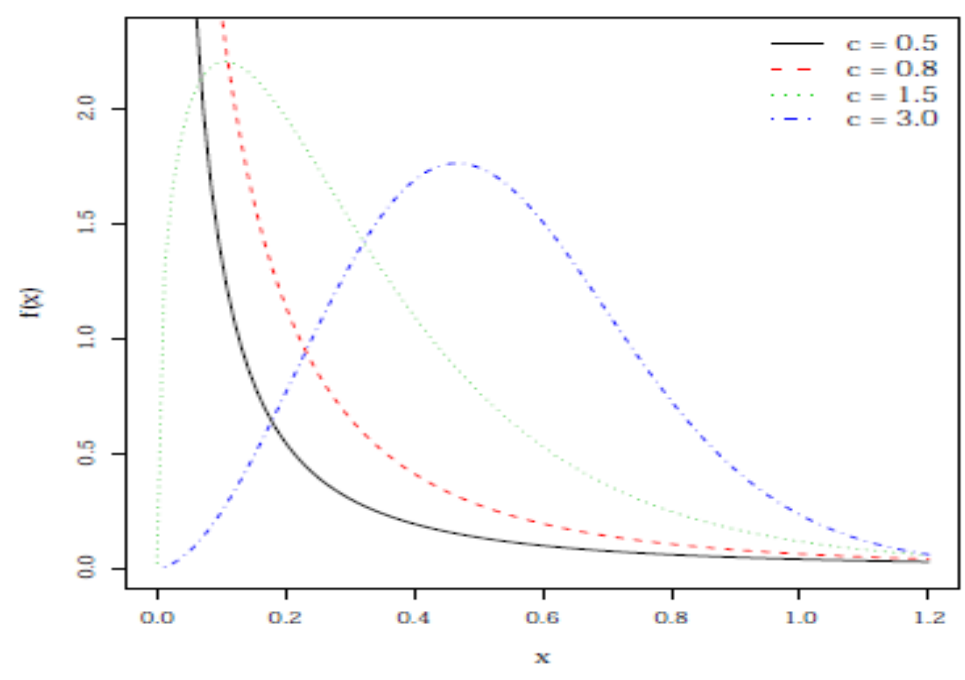

(b) For $a=1.5$ and $d=3$

Figure 3: Pdf plots for the RBXII model for $s=1$

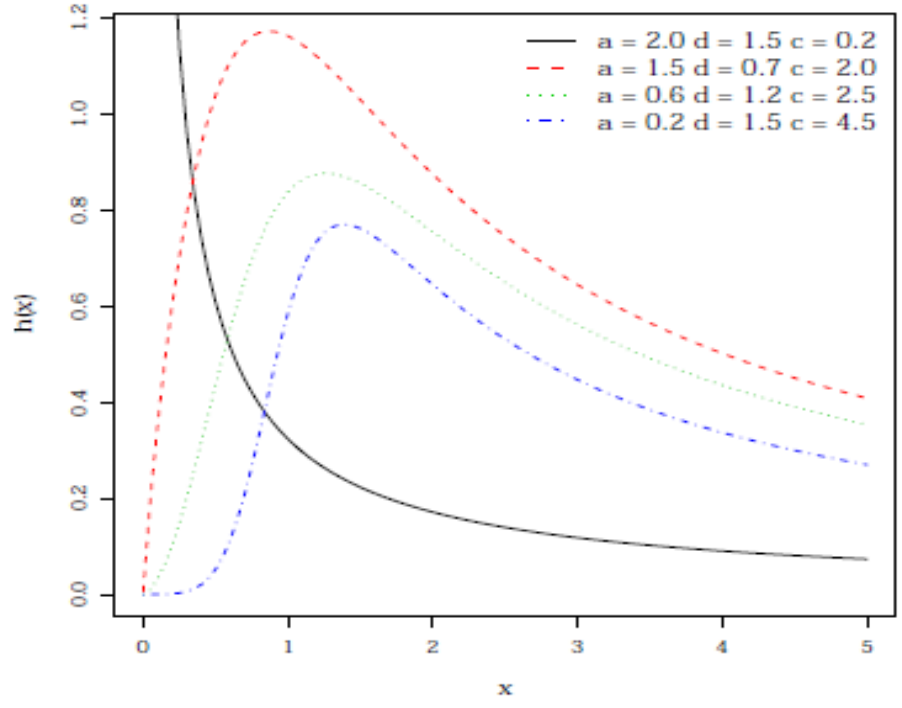

(a)

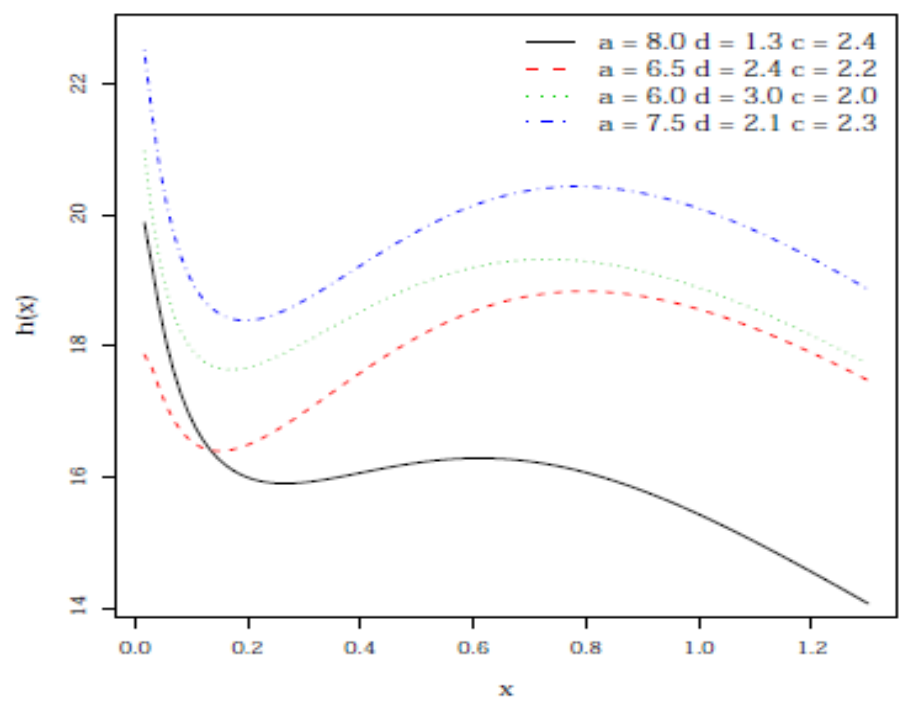

(b)

Figure 4: Hrf plots for the RBXII model 
distribution has the same forms for the hrf of the ZBXII distribution and also has various forms for its pdf. However, its hrf is less flexible that one of the the ZBXII model.

\section{Useful expansions}

We derive some useful expansions for equations (4) and (5). For any real parameter $m$ and $z \in(0,1)$, the following formula holds

$$
[-\log (1-z)]^{m}=z^{m}+\sum_{i=0}^{\infty} p_{i}(m) z^{i+m+1}
$$

where $p_{0}(m)=m / 2, p_{1}(m)=m(3 m+5) / 24, p_{2}(m)=m\left(m^{2}+5 m+6\right) / 48, p_{3}(m)=$ $m\left(15 m^{3}+150 m^{2}+485 m+502\right) / 5760$, etc, are Stirling polynomials. Castellares and Lemonte (2015) gave a recursive expression for these coefficients. The proof is given in details by Flajolet and Odlyzko (1990) (see Theorem 3A, page 227) and Flajolet and Sedgewick (2009) (see Theorem VI.2, page 385). By inserting (8) in equation (2), the ZBXII density can be expressed as

$$
f(x)=c d s^{-c} x^{c-1}\left[1+\left(\frac{x}{s}\right)^{c}\right]^{-d-1} \sum_{k=0}^{\infty} b_{k}\left\{1-\left(\left(1+\left(\frac{x}{s}\right)^{c}\right]^{-d}\right\}^{a+k-1},\right.
$$

where $b_{0}=1 / \Gamma(a), b_{1}=p_{0}(a-1) / \Gamma(a), b_{2}=p_{1}(a-1) / \Gamma(a), b_{3}=p_{2}(a-1) / \Gamma(a)$, etc. If $|z|<1$ and $b>0$ is real non-integer, the power series holds

$$
(1-z)^{b-1}=\sum_{r=0}^{\infty}(-1)^{r}\left(\begin{array}{c}
b-1 \\
r
\end{array}\right) z^{r} .
$$

Using the above series for $\left\{1-\left[1+(x / s)^{c}\right]^{-d}\right\}^{a+k-1}$ in (9) and after some algebraic manipulation, we have

$$
f(x)=\sum_{r=0}^{\infty} w_{r} g(x ; s,(r+1) d, c)
$$

where

$$
w_{r}=\sum_{k=0}^{\infty} \frac{(-1)^{r} b_{k} \Gamma(a+k)}{\Gamma(a+k-r) r !(r+1)}
$$

and $g(x ; s,(r+1) d, c)$ is the BXII density function with scale parameter $s$ and shape parameters $c$ and $(r+1) d$. Equation (10) reveals that the ZBXII density is an infinite linear combination of BXII densities. So, several structural properties of the ZBXII distribution can follow from those BXII properties. By integrating equation (10) gives

$$
F(x)=\sum_{r=0}^{\infty} w_{r} G(x ; s,(r+1) d, c) .
$$


Equations (10) and (11) are the main results of this section.

\section{Quantile function}

By inverting (4), we obtain an explicit expression for the quantile function (qf) of the ZBXII distribution, say $Q(u)$, as

$$
Q(u)=s\left\{\exp \left[\frac{1}{d} Q^{-1}(a, 1-u)\right]-1\right\}^{1 / c}
$$

where $Q^{-1}(a, u)$ is the inverse function of $Q(a, x)=1-\gamma(a, x) / \Gamma(a)$. Quantities of interest can be obtained from (12) by substituting appropriate values for $u$.

\section{Moments and generating function of $\mathrm{X}$}

The $n$th moment of $X$ follows directly from (10) using a result in Zimmer et al. (1998). For $n<c d$, we have

$$
\mu_{n}^{\prime}=s^{n} d \sum_{r=0}^{\infty}(r+1) w_{r} B\left((r+1) d-n c^{-1}, 1+n c^{-1}\right) .
$$

The central moments $\left(\mu_{s}\right)$ and cumulants $\left(\kappa_{s}\right)$ of $X$ can be expressed from (13) as

$$
\mu_{s}=\sum_{i=0}^{s}\left(\begin{array}{l}
s \\
i
\end{array}\right)(-1)^{i} \mu_{1}^{\prime s} \mu_{s-i}^{\prime} \quad \text { and } \quad \kappa_{s}=\mu_{s}^{\prime}-\sum_{i=1}^{s-1}\left(\begin{array}{c}
s-1 \\
i-1
\end{array}\right) \kappa_{i} \mu_{s-i}^{\prime}
$$

respectively, where $\kappa_{1}=\mu_{1}^{\prime}$. Thus, $\kappa_{2}=\mu_{2}^{\prime}-\mu_{1}^{\prime 2}, \kappa_{3}=\mu_{3}^{\prime}-3 \mu_{2}^{\prime} \mu_{1}^{\prime}+2 \mu_{1}^{\prime 3}, \kappa_{4}=\mu_{4}^{\prime}-$ $4 \mu_{3}^{\prime} \mu_{1}^{\prime}-3 \mu_{2}^{\prime 2}+12 \mu_{2}^{\prime} \mu_{1}^{\prime 2}-6 \mu_{1}^{\prime 4}$, etc. The skewness $\gamma_{1}=\kappa_{3} / \kappa_{2}^{3 / 2}$ and kurtosis $\gamma_{2}=\kappa_{4} / \kappa_{2}^{2}$ can be calculated from the third and fourth standardized cumulants.

Expressions for the skweness and kurtosis may be obtained from (12). The Bowley's skewness is based on quartiles, and Kenney and Keeping (1962) proposed the quantity

$$
B=\frac{Q(3 / 4)-2 Q(1 / 2)+Q(1 / 4)}{Q(3 / 4)-Q(1 / 4)}
$$

whereas the Moors' kurtosis (Moors, 1988), based on octiles, is given by

$$
M=\frac{Q(7 / 8)-Q(5 / 8)-Q(3 / 8)+Q(1 / 8)}{Q(6 / 8)-Q(2 / 8)} .
$$

Plots of the skewness and kurtosis of $X$ as functions of $a$ and $d$ for selected values of $c$ and $s=1$ are displayed in Figure 5. It suggests that Bowley's skewness and Moors' kurtosis increases and stabilizes when the parameters $a$ and $d$ increase and $c$ is not very large. For 

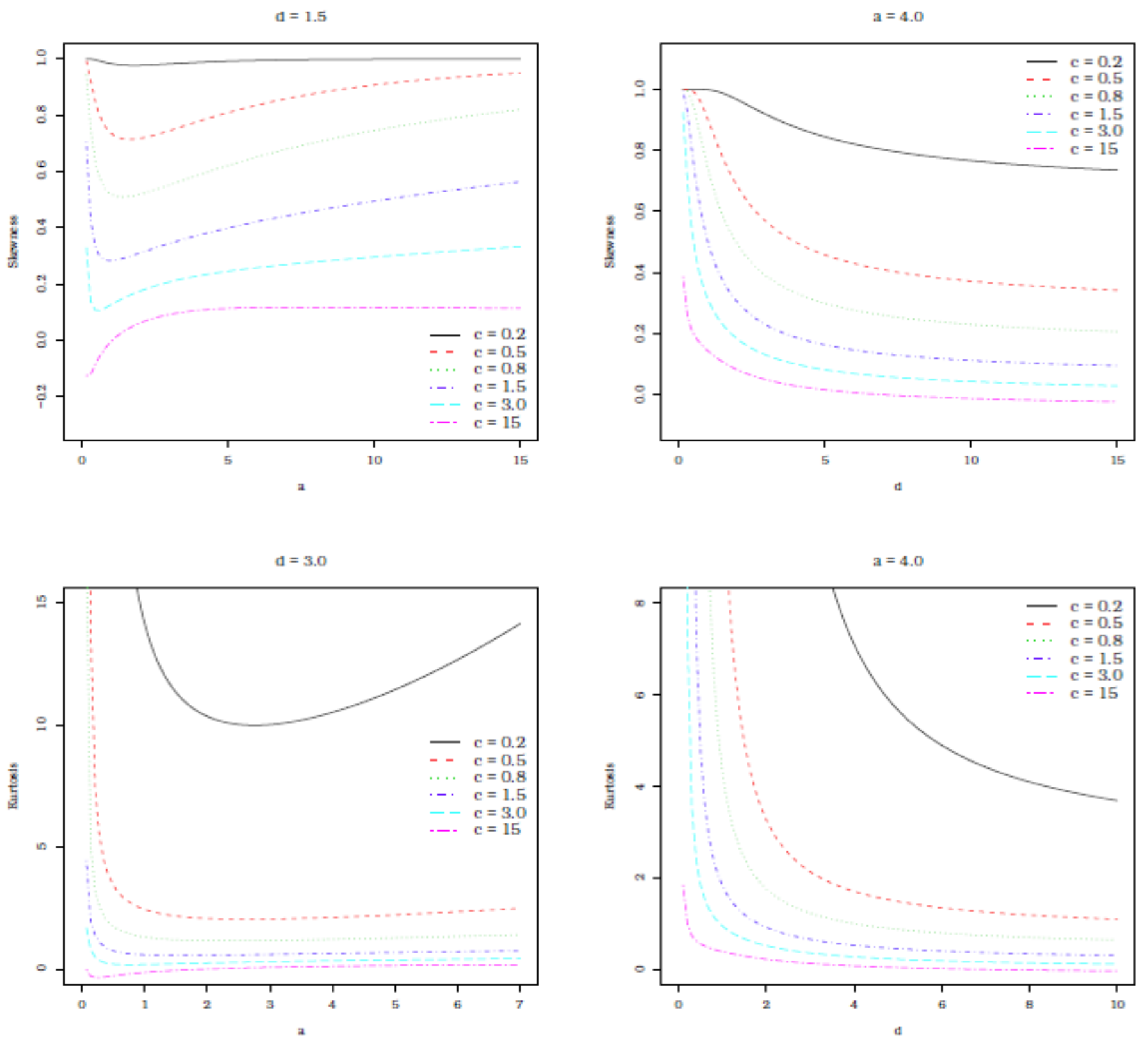

Figure 5: Skewness and kurtosis of $X$ for some parameter values. 
$c=0.2$, the Bowley's skewness seems to be little affected, while Moors' kurtosis takes more elevated values. For higher values of $c$, we note that Bowley's skewness gets negative values and the Moors' kurtosis decreases towards to zero.

The $h$ th incomplete moment of $X$ is defined by $T_{h}(y)=\int_{0}^{y} x^{h} f(x) d x$. By using (10), we obtain

$$
T_{h}(y)=c d \sum_{r=0}^{\infty}(r+1) w_{r} \int_{0}^{y} x^{h-1}\left(\frac{x}{s}\right)^{c}\left[1+\left(\frac{x}{s}\right)^{c}\right]^{-(r+1) d-1} d x .
$$

Setting $t=\left[1+\left(\frac{x}{s}\right)^{c}\right]^{-1}$ in the last equation, we have

$$
T_{h}(y)=d s^{h} \sum_{r=0}^{\infty}(r+1) w_{r} \int_{s^{c} /\left(s^{c}+y^{c}\right)}^{1} t^{(r+1) d-\frac{h}{c}-1}(1-t)^{\frac{h}{c}} d t .
$$

Hence, the $h$ th incomplete moment of $X$ reduces to

$$
T_{h}(y)=d s^{h} \sum_{r=0}^{\infty}(r+1) w_{r} B_{s^{c} / s^{c}+y^{c}}\left((r+1) d-h c^{-1}, 1+h c^{-1}\right),
$$

where $B_{z}(a, b)=\int_{z}^{1} t^{a-1}(1-t)^{b-1} d t$ is the upper incomplete beta function.

Let $M_{d}(t)$ be the moment generating function (mgf) of the $\operatorname{BXII}(s, k, c)$ distribution. The mgf $M(t)$ of $X$ can be obtained from (10) as an infinite weighted sum

$$
M(t)=\sum_{r=0}^{\infty} w_{r} M_{(r+1) d}(t),
$$

where $M_{(r+1) d}(t)$ is the $\operatorname{mgf}$ of the $\operatorname{BXII}(s,(r+1) d, c)$ distribution. For $t<0$, Paranaíba et al. $(2011,2013)$ provided the following representation for $M_{d}(t)$

$$
M_{d}(t)=c d \int_{0}^{\infty} \exp (y s t) y^{c-1}\left(1+y^{c}\right)^{-(d+1)} d y .
$$

For calculating $M_{d}(t)$, we require the Meijer G-function defined by

$$
G_{p, q}^{m, n}\left(x \mid \begin{array}{l}
a_{1}, \ldots, a_{p} \\
b_{1}, \ldots, b_{q}
\end{array}\right)=\frac{1}{2 \pi i} \int_{L} \frac{\prod_{j=1}^{m} \Gamma\left(b_{j}+t\right) \prod_{j=1}^{n} \Gamma\left(1-a_{j}-t\right)}{\prod_{j=n+1}^{p} \Gamma\left(a_{j}+t\right) \prod_{j=m+1}^{p} \Gamma\left(1-b_{j}-t\right)} x^{-t} d t
$$

where $\mathrm{L}$ denotes an integration path and $\mathrm{i}=\sqrt{-1}$ is the complex unit, see Section 9.3 in Gradshteyn and Ryzhik (2000). Many integrals with elementary and special functions are particular cases of the Meijer G-function (Prudnikov et al., 1986). If we assume that 
$c=m / d$, where $m$ and $d$ are positive integers, $\mu>-1$ and $p>0$, we have the following result from Prudnikov et al. (1992), page 21.

$$
\begin{aligned}
I\left(p, \mu, \frac{m}{d}, \nu\right)= & \int_{0}^{\infty} \mathrm{e}^{-p x} x^{\mu}\left(1+x^{\frac{m}{d}}\right)^{\nu} d x \\
= & \frac{d^{-\nu} m^{\mu+\frac{1}{2}}}{(2 \pi)^{\frac{(m-1)}{2}} \Gamma(-\nu) p^{\mu+1}} \times \\
& G_{d+m, d}^{d, d+m}\left(\frac{m^{m}}{p^{m}} \mid \begin{array}{l}
\Delta(m,-\mu), \Delta(d, \nu+1) \\
\Delta(d, 0)
\end{array}\right),
\end{aligned}
$$

where $\Delta(d, a)=\frac{a}{d}, \frac{a+1}{d}, \cdots, \frac{a+d}{d}$. Using the integral in (16), we obtain

$$
M_{d}(t)=m I\left(-s t, \frac{m}{d}-1, \frac{m}{d},-d-1\right) .
$$

This condition is not restrictive since every positive real number can be approximated by a rational number. See Paranaíba et al. $(2011,2013)$ for the special cases $c=1$ and $c=2$. Hence, for $t<0$, the generating function of $X$ follows from (15) as

$$
M(t)=m \sum_{r=0}^{\infty} w_{r} I\left(-s t, \frac{m}{(r+1) d}-1, \frac{m}{(r+1) d},-(r+1) d-1\right) .
$$

Equations (13), (14), (15) and (17) are the main results of this section.

\section{Mean deviations}

The deviations from the mean and the median are commonly used as measures of spread in a population. The mean deviations about the mean and the median of $X$ can be determined as

$$
\delta_{1}=2 \mu_{1}^{\prime} F\left(\mu_{1}^{\prime}\right)-2 T_{1}\left(\mu_{1}^{\prime}\right) \quad \text { and } \quad \delta_{2}=\mu_{1}^{\prime}-2 T_{1}(M),
$$

respectively, where $\mu_{1}^{\prime}=\mathbb{E}(X)$, the median $M$ of $X$ follows from (12) by $M=Q(1 / 2), F\left(\mu_{1}^{\prime}\right)$ is easily obtained from (4) and $T_{1}(y)=\int_{0}^{y} x f(x) \mathrm{d} x$ is the first incomplete moment. Hence, it follows from (14) that

$$
T_{1}(y)=d s \sum_{r=0}^{\infty}(r+1) w_{r} B_{s^{c} / s^{c}+y^{c}}\left((r+1) d-c^{-1}, 1+c^{-1}\right) .
$$

An alternative expression for $T_{1}(y)$, using (10), takes the form

$$
T_{1}(y)=c d s^{-c} \sum_{r=0}^{\infty}(r+1) w_{r} \int_{0}^{y} x^{c}\left[1+\left(\frac{x}{s}\right)^{c}\right]^{-(r+1) d-1} \mathrm{~d} x .
$$


Setting $u=(x / s)^{c}$, we obtain

$$
\begin{aligned}
T_{1}(y) & =d s \sum_{r=0}^{\infty}(r+1) w_{r} \int_{0}^{\left(\frac{y}{s}\right)^{c}} u^{1 / c}(1+u)^{-(r+1) d-1} \mathrm{~d} u . \\
& =\frac{c d s y^{c+1}}{1+c} \sum_{r=0}^{\infty}(r+1) w_{r 2} F_{1}\left[1+\frac{1}{c},(r+1) d+1 ; 2+\frac{1}{c} ;-\left(\frac{y}{s}\right)^{c}\right],
\end{aligned}
$$

where ${ }_{2} F_{1}$ is the hypergeometric function defined by

$$
{ }_{2} F_{1}(a, b ; c ; x)=\sum_{k=0}^{\infty} \frac{(a)_{k}(b)_{k}}{(c)_{k}} \frac{x^{k}}{k !},
$$

where $|x|<1, c=0,-1,-2, \ldots$ and $(z)_{n}$ is the Pochhammer polynomial.

The previous results are related to the Bonferroni and Lorenz curves. For a given probability $\pi$, they are defined as $B(\pi)=T_{1}(q) / \pi \mu_{1}^{\prime}$ and $L(\pi)=T_{1}(q) / \mu_{1}^{\prime}$, respectively, where $q=Q(\pi)$ is given by (12). If $\pi$ is the proportion of units whose income is lower than or equal to $q$, the values of $L(\pi)$ yield fractions of the total income and $B(\pi)$ refers to the relative income levels. These curves are important in economics for studying income and poverty, but can be useful in demography, reliability, insurance, medicine and several other fields.

The Lorenz curve also allows to obtain the Gini concentration $\left(C_{G}\right)$, given by

$$
C_{G}=1-2 \int_{0}^{1} L(\pi) \mathrm{d} u
$$

and represents the area between the curve $L(\pi)$ and the straight line.

\section{Maximum-likelihood estimation}

This section addresses the estimation of the unknown parameters of the ZBXII distribution by the method of maximum likelihood. Let $x_{1}, \ldots, x_{n}$ be a random sample of size $\mathrm{n}$ from the $\operatorname{ZBXII}(a, c, d, s)$ distribution. Let $\boldsymbol{\theta}=(a, c, d, s)^{T}$ be the parameter vector of interest. The log-likelihood function for $\boldsymbol{\theta}$ can be expressed as

$$
\begin{aligned}
\ell(\boldsymbol{\theta})= & n \log \left[\frac{c d^{a}}{s \Gamma(a)}\right]+(c-1) c^{-1} \sum_{i=1}^{n} \log \left(u_{i}-1\right) \\
& -(d+1) \sum_{i=1}^{n} \log \left(u_{i}\right)+(a-1) \sum_{i=1}^{n} \log \left[\log \left(u_{i}\right)\right],
\end{aligned}
$$


where $u_{i}=1+\left(\frac{x_{i}}{s}\right)^{c}$. The components of the score vector $\boldsymbol{U}(\boldsymbol{\theta})$ are given by

$$
\begin{aligned}
U_{a}(\boldsymbol{\theta}) & =n[\log (d)-\psi(a)]+\sum_{i=1}^{n} \log \left[\log \left(u_{i}\right)\right], \\
U_{c}(\boldsymbol{\theta}) & =\frac{n}{c}+c^{-1} \sum_{i=1}^{n} \log \left(u_{i}-1\right)-\frac{d+1}{c} \sum_{i=1}^{n} \frac{\left(u_{i}-1\right) \log \left(u_{i}-1\right)}{u_{i}} \\
& +\frac{a-1}{c} \sum_{i=1}^{n} \frac{\left(u_{i}-1\right) \log \left(u_{i}-1\right)}{u_{i} \log \left(u_{i}\right)}, \\
U_{d}(\boldsymbol{\theta}) & =\frac{a n}{d}-\sum_{i=1}^{n} \log \left(u_{i}\right), \\
\text { and } & \\
U_{s}(\boldsymbol{\theta}) & =\frac{-n c}{s}+\frac{c(d+1)}{s} \sum_{i=1}^{n} \frac{\left(u_{i}-1\right)}{u_{i}}-\frac{c(a-1)}{s} \sum_{i=1}^{n} \frac{\left(u_{i}-1\right)}{u_{i} \log \left(u_{i}\right)},
\end{aligned}
$$

where $\psi($.$) is the digamma function.$

Setting these expressions to zero, say $\boldsymbol{U}(\boldsymbol{\theta})=\mathbf{0}$, and solving them simultaneously yields the maximum likelihood estimators (MLEs) of the unknown parameters. These equations can not be solved analytically. We have to use iterative techniques such as the quasi-Newton BFGS and Newton-Raphson algorithms, see Press et al. (2007).

For fixed $c, d$ and $s$, the MLE of $a$ is given by

$$
\hat{a}(\hat{c}, \hat{d}, \hat{s})=\psi^{-1}\left(\sum_{i=1}^{n} \frac{\log \left[\log \left(u_{i}\right)\right]}{n}-\log (d)\right),
$$

where $\psi^{-1}($.$) is the inverse digamma function. By replacing a$ by $\hat{a}$ in equation (18), we obtain the profile log-likelihood function for $\boldsymbol{\theta}_{p_{1}}=(c, d, s)$, expressed by

$$
\begin{aligned}
\ell\left(\boldsymbol{\theta}_{\boldsymbol{p}_{\mathbf{1}}}\right)= & (c-1) c^{-1} \sum_{i=1}^{n} \log \left(u_{i}-1\right)+n\left[\log \left(\frac{c}{s}\right)+\log (d) \psi^{-1}\left(\sum_{i=1}^{n} \frac{\log \left[\log \left(u_{i}\right)\right]}{n}-\log (d)\right)\right] \\
& -n \log \left\{\Gamma\left[\left(\psi^{-1}\left(\sum_{i=1}^{n} \frac{\log \left[\log \left(u_{i}\right)\right]}{n}-\log (d)\right)\right]\right\}-(d+1) \sum_{i=1}^{n} \log \left(u_{i}\right)\right. \\
& +\left[\psi^{-1}\left(\sum_{i=1}^{n} \frac{\log \left[\log \left(u_{i}\right)\right]}{n}-\log (d)\right)-1\right] \sum_{i=1}^{n} \log \left[\log \left(u_{i}\right)\right] .
\end{aligned}
$$


This first profile log-likelihood may be helpful for obtaining the initial values for the parameters by fitting the BXII distribution and using the relationship in (19) for $a$. Alternatively, for fixed $a, c$ and $s$, we obtain the MLE of $d$ as

$$
\hat{d}(\hat{a}, \hat{c}, \hat{s})=a n\left[\sum_{i=1}^{n} \log \left(u_{i}\right)\right]^{-1}
$$

and by replacing $d$ by $\hat{d}$ in equation (18), we have the profile log-likelihood function for $\boldsymbol{\theta}_{p_{\mathbf{2}}}=(a, c, s)$. It can be expressed as

$$
\begin{aligned}
\ell\left(\boldsymbol{\theta}_{\boldsymbol{p}_{\mathbf{2}}}\right)= & n\left\{\log \left[\frac{c}{s \Gamma(a)}\left(\frac{\sum_{i=1}^{n} \log \left(u_{i}\right)}{a n}\right)^{-a}\right]-a\right\}+(c-1) c^{-1} \sum_{i=1}^{n} \log \left(u_{i}-1\right) \\
& +(a-1) \sum_{i=1}^{n} \log \left[\log \left(u_{i}\right)\right]-\sum_{i=1}^{n} \log \left(u_{i}\right) .
\end{aligned}
$$

We can note that (21) is simpler than (20) and might be a useful option for the parameter estimation of the ZBXII distribution.

For interval estimation of the components of $\boldsymbol{\theta}$, we can adopt the observed information matrix $\boldsymbol{J}(\boldsymbol{\theta})$ given by

$$
\boldsymbol{J}(\boldsymbol{\theta})=-\frac{\partial^{2} \ell(\theta)}{\partial \theta \partial \theta^{T}}=\left(\begin{array}{cccc}
J_{a a} & J_{a s} & J_{a d} & J_{a c} \\
\cdot & J_{s s} & J_{s d} & J_{s c} \\
\cdot & \cdot & J_{d d} & J_{d c} \\
\cdot & \cdot & \cdot & J_{c c}
\end{array}\right)
$$

whose elements can be obtained from the authors upon request. Under standard regularity conditions, the multivariate normal $N_{4}\left(0, \boldsymbol{J}(\widehat{\boldsymbol{\theta}})^{-1}\right)$ distribution can be used to construct approximate confidence intervals for the model parameters.

We are able to compute the maximized unrestricted and restricted log-likelihoods to obtain likelihood ratio (LR) statistics for testing goodness-of-fit of the ZBXII model with its sub-models. For example, we may use LR statistics to check if the fitted ZBXII distribution for a given data set is statistically "superior" to the fitted BXII, LL and Weibull distributions. In any case, hypothesis tests of the type $H_{0}: \boldsymbol{\theta}=\boldsymbol{\theta}_{0}$ versus $H: \boldsymbol{\theta} \neq \boldsymbol{\theta}_{0}$ can be performed using LR statistics. For example, the LR statistic for testing $H_{0}: a=1$ versus $H: a \neq 1$, which is equivalent to compare the ZBXII and BXII distributions, is given by

$$
w=2\{l(\widehat{a}, \widehat{s}, \widehat{d}, \widehat{c})-l(1, \widetilde{s}, \widetilde{d}, \widetilde{c})\}
$$

where $\widehat{a}, \widehat{s}, \widehat{d}$ and $\widehat{c}$ are the MLEs under $H$ and $\widetilde{s}, \widetilde{d}$ and $\widetilde{c}$ are the estimates under $H_{0}$.

\section{Simulation study}


We perform a Monte Carlo simulation to evaluate some asymptotic properties of the MLEs for the parameters of the ZBXII distribution. We generate the ZBXII model for three different combinations of $a, c, d$ and $s$ with samples of sizes $n=250,500$ and repeat the simulation $N=10,000$ times. We use the subroutine optim in $\mathrm{R}$ for maximizing the loglikelihood in (18). Table 2 gives the mean estimates of the MLEs and their root mean squared errors (RMSEs). As expected, the MLEs tend to be closer to the true parameters and the RMSEs decrease as the sample size $n$ increases.

Table 2: Monte Carlo results for the mean estimates and RMSEs

\begin{tabular}{cc|rrrr|rrrr}
\hline & & \multicolumn{6}{|c|}{ Mean } & \multicolumn{4}{|c|}{ RMSE } \\
\cline { 3 - 10 } $\boldsymbol{\theta}$ & $n$ & $\hat{a}$ & $\hat{c}$ & $\hat{d}$ & $\hat{s}$ & $\hat{a}$ & $\hat{c}$ & $\hat{d}$ & $\hat{s}$ \\
\hline$(0.3,1.7,0.2,0.2)$ & 250 & 0.345 & 1.710 & 0.255 & 0.205 & 0.164 & 0.489 & 0.206 & 0.069 \\
& 500 & 0.319 & 1.703 & 0.222 & 0.202 & 0.085 & 0.338 & 0.089 & 0.043 \\
\hline$(0.5,1.2,0.1,0.3)$ & 250 & 0.537 & 1.232 & 0.109 & 0.323 & 0.162 & 0.315 & 0.043 & 0.193 \\
& 500 & 0.517 & 1.213 & 0.104 & 0.310 & 0.097 & 0.160 & 0.027 & 0.127 \\
\hline$(0.9,1.5,0.3,0.1)$ & 250 & 1.125 & 1.599 & 0.348 & 0.099 & 0.764 & 0.905 & 0.203 & 0.050 \\
& 500 & 0.984 & 1.519 & 0.323 & 0.099 & 0.337 & 0.271 & 0.114 & 0.035 \\
\hline
\end{tabular}

\section{Applications}

In this section, we present two applications to real data sets for illustrating the potentiality of the new distribution for modeling positive data. First, we consider the stress-rupture life of kevlar 49/epoxy strands which are subjected to constant sustained pressure at the $90 \%$ stress level until all had failed. The real data set consists in 101 data points such that we obtain the exact failure times in hours. Andrews and Herzberg (1985), Cooray and Ananda (2008) and, more recently, Paranaíba et al. (2013) also analyzed these data.

The second data set represents the strengths of $1.5 \mathrm{~cm}$ glass fibres measured at the National Physical Laboratory, England. It has 51 observations and is available for download at http://www.stat.ncsu.edu/research/sas/sicl/data/. These data were previously analysed by Smith and Naylor (1987), Cordeiro and Lemonte (2011) and Paranaíba et al. (2013), among others.

We compare the ZBXII distribution with some other competitive models. One of these models is the KwBXII distribution, whose pdf is given by

$$
\begin{aligned}
f(x)= & a b c k s^{-c} x^{c-1}\left[1+\left(\frac{x}{s}\right)^{c}\right]^{-k-1}\left\{1-\left[1+\left(\frac{x}{s}\right)^{c}\right]^{-k}\right\}^{a-1} \times \\
& {\left[1-\left\{1-\left[1+\left(\frac{x}{s}\right)^{c}\right]^{-k}\right\}^{a}\right]^{b-1}, x>0, }
\end{aligned}
$$


where $a>0$ and $b>0$ are shape parameters. The BBXII model has pdf given by

$$
f(x)=\frac{c k(x)^{c-1}}{s^{c} B(a, b)}\left\{1-\left[1+(x / s)^{c}\right]^{-k}\right\}^{a-1}\left[1+(x / s)^{c}\right]^{-(k b+1)},
$$

where $a$ and $b$ are shape parameters.

Introduced by Mudholkar and Srivastava (1993), the exponentiated Weibull (EW) distribution is a popular distribution in lifetime data, whose pdf is given by

$$
g(t)=\alpha \beta \lambda t^{\alpha-1} \exp \left(-\lambda t^{\alpha}\right)\left[1-\exp \left(-\lambda t^{\alpha}\right)\right]^{\beta-1}, \quad t>0,
$$

where $\alpha>0$ and $\beta>0$ are shape parameters and $\lambda>0$ is a scale parameter. The Weibull (W) model arises from the EW model when $\beta=1$.

We estimate the model parameters of the ZBXII (5), BXII and LL models and the above competitive models by the maximum likelihood method. Furthermore, we use the Akaike information criteria (AIC), consistent Akaike information criteria (CAIC), Bayesian information criteria (BIC), Hannan-Quinn information criteria (HQIC), Kolmogorov-Smirnov (KS), corrected Cramér-von Mises $\left(W^{*}\right)$ and corrected Anderson-Darling $\left(A^{*}\right)$ statistics as goodnessof-fit statistics for these models. The lower are these statistics, the better is the adjustment to the data. The MLEs and goodness-of-fit statistics are obtained using the AdequacyModel script in R software (Marinho et al., 2016).

\subsection{Stress data}

Table 3 provides a descriptive summary of the stress data. It has positive skewness and large kurtosis. The mean and median are close but smaller than standard deviation (SD) and variance. Moreover, the amplitude is elevated if compared with the other descriptive statistics.

Table 3: Descriptive statistics for stress data.

\begin{tabular}{cccccccc}
\hline Mean & Median & SD & Variance & Skewness & Kurtosis & Min. & Max. \\
\hline 1.03 & 0.80 & 1.12 & 1.25 & 3.05 & 14.51 & 0.01 & 7.89 \\
\hline
\end{tabular}

Table 4 lists the MLEs (and the corresponding standard errors of the estimates) of the unknown parameters for the fitted models. We note that the estimated standard errors of $\hat{s}$ in the BXII distribution is large. Further, the parameter estimates for the models BBXII, KwBXII and ZBXII are close.

According to the goodness-of-fit statistics (Table 5), the ZBXII distribution provides a good fit and is quite competitive with the BBXII and KwBXII models for these data. Considering the AIC, CAIC, BIC and HQIC, the ZBXII distribution yields a better fit than the other distributions. Based on the KS, $W^{*}$ and $A^{*}$ statistics, it is quite competitive to the 
Table 4: The MLEs of the model parameters for stress data and corresponding standard errors in parentheses.

\begin{tabular}{lccccc}
\hline & $\mathrm{c}$ & $\mathrm{d}$ & $\mathrm{s}$ & $\mathrm{a}$ & $\mathrm{b}$ \\
\hline BBXII & 6.7846 & 0.5625 & 1.6275 & 0.1042 & 0.6052 \\
& $(0.0023)$ & $(0.0032)$ & $(0.0198)$ & $(0.0111)$ & $(0.1172)$ \\
KwBXII & 6.81899 & 0.54959 & 1.53837 & 0.09036 & 0.68182 \\
& $(0.0155)$ & $(0.0051)$ & $(0.0155)$ & $(0.0131)$ & $(0.0835)$ \\
ZBXII & 6.7147 & 0.2472 & 1.7822 & 0.1059 & \\
& $(0.0606)$ & $(0.0557)$ & $(0.0163)$ & $(0.0109)$ & \\
BXII & 0.9956 & 6.0925 & 5.2208 & & \\
& $(0.0781)$ & $(2.9914)$ & $(2.9612)$ & & \\
& $\mathrm{c}$ & $\mathrm{m}$ & & & \\
LL & 1.270 & 0.624 & & & \\
& $(0.1069)$ & $(0.0849)$ & & & \\
EW & $\lambda$ & $\alpha$ & $\beta$ & & \\
W & 0.8212 & 1.0605 & 0.7931 & & \\
& $(0.2658)$ & $(0.2404)$ & $(0.2877)$ & & \\
\hline
\end{tabular}

KwBXII model. Figure 6.a displays some plots of the estimated densities and Figure 6.b the estimated and empirical cumulative functions for the most competitive models. They reveal a good adjustment for these data of the estimated densities and estimated and empirical cumulative functions of the BBXII, KwBXII and ZBXII distributions. Under close results in terms of MLEs, the last one presents better results for the information criteria and has one less parameter. In conclusion, these results reveal that the ZBXII distribution can be used effectively to provide better fits than other lifetime models and it is a competitive alternative for the W, LL and BXII distributions, among others.

\subsection{Fibres data}

Table 6 gives a descriptive summary for the fibres data. The mean and median are close and we have small values for SD and variance. It has negative skewness, positive kurtosis and lower variability than the first data set. We can also note that the amplitude is 1.69 for these data.

The MLEs of the model parameters for fibres data (with standard errors of the estimates) are listed in Table 7 for the fitted models. Table 8 presents the goodness-of-fit statistics and reveals that the ZBXII distribution yields a good adjustment for the fibres data. It has the lower values for all statistics but BIC and is quite competitive to the $\mathrm{W}$ distribution and other BXII generalizations. The plots of the estimated densities and estimated empirical 


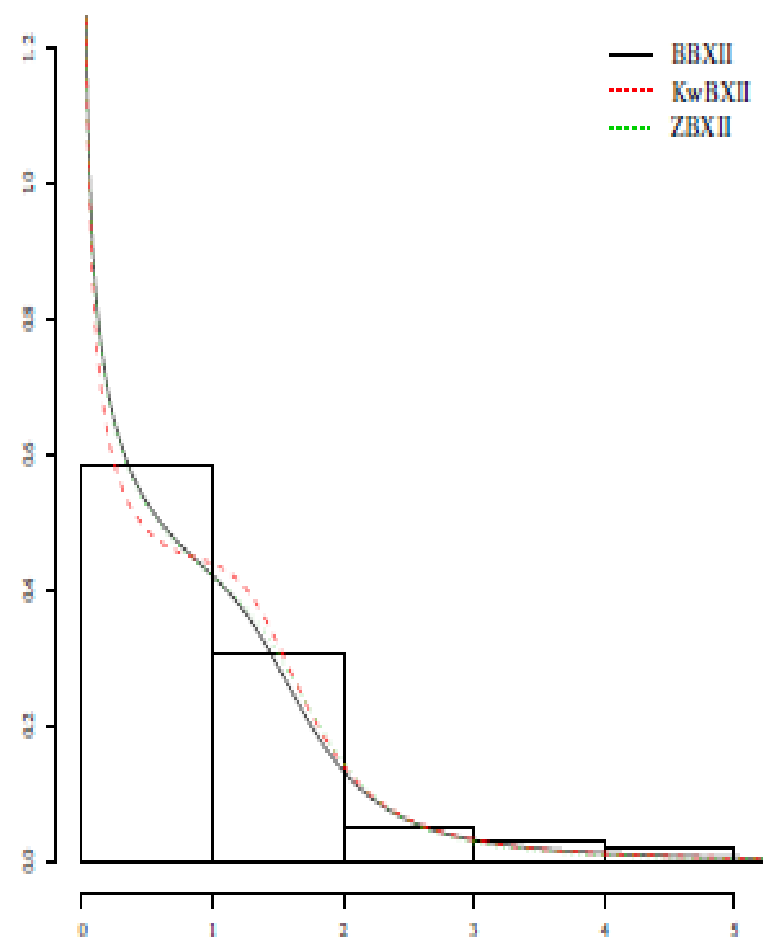

(a)

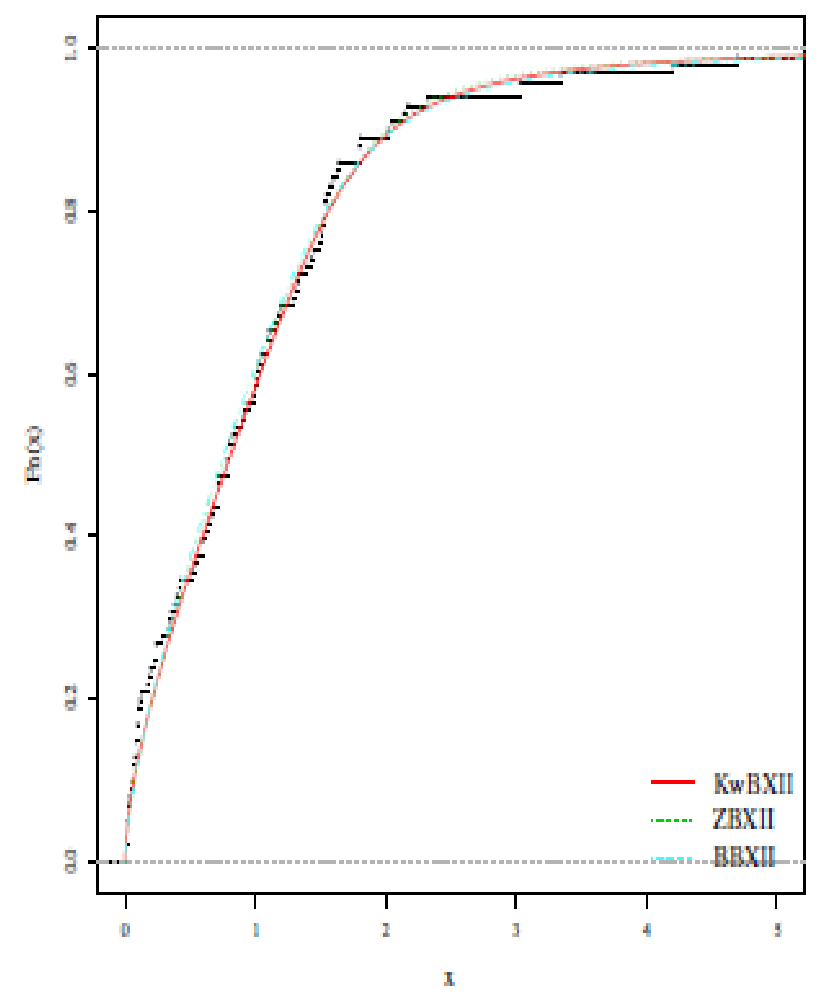

(b)

Figure 6: (a) Estimated densities of the BBXII, KwBXII and ZBXII models for stress data; (b) estimated and empirical cumulative functions of these models for stress data 
Table 5: Goodness-of-fit statistics for the fitted models for stress data.

\begin{tabular}{lccccccc}
\hline & AIC & CAIC & BIC & HQIC & $W^{*}$ & $A^{*}$ & KS \\
\hline BBXII & 206.8734 & 207.5050 & 219.9490 & 212.1668 & 0.0563 & 0.3871 & 0.0637 \\
KwBXII & 206.9635 & 207.5951 & 220.0391 & 212.2569 & $\mathbf{0 . 0 3 6 5}$ & $\mathbf{0 . 3 1 1 0}$ & $\mathbf{0 . 0 6 1 9}$ \\
ZBXII & $\mathbf{2 0 4 . 0 9 6 5}$ & $\mathbf{2 0 4 . 5 1 3 2}$ & $\mathbf{2 1 4 . 5 5 7 0}$ & $\mathbf{2 0 8 . 3 3 1 2}$ & 0.0461 & 0.3412 & 0.0667 \\
BXII & 211.9727 & 212.2201 & 219.8181 & 215.1487 & 0.2021 & 1.1268 & 0.0910 \\
LL & 229.3724 & 229.4948 & 234.6026 & 231.4898 & 0.5654 & 3.0709 & 0.1113 \\
EW & 211.5743 & 211.8218 & 219.4197 & 214.7504 & 0.1652 & 0.9586 & 0.0844 \\
W & 209.9536 & 210.0761 & 215.1839 & 212.0710 & 0.1987 & 1.1113 & 0.0906 \\
\hline
\end{tabular}

Table 6: Descriptive statistics for fibres data.

\begin{tabular}{cccccccc}
\hline Mean & Median & SD & Variance & Skewness & Kurtosis & Min. & Max. \\
\hline 1.44 & 1.52 & 0.33 & 0.11 & -0.64 & 0.80 & 0.55 & 2.24 \\
\hline
\end{tabular}

cumulative functions for the most competitive models are displayed in Figure 7. We can note that the ZBXII distribution is more accurate in the central measurements, being superior to the $\mathrm{W}$ and KwBXII distributions for modeling this data set. Then, we can conclude that the ZBXII distribution provides a better adjustment than the other current distributions and then it is a good alternative for modeling these data.

\section{The RBXII distribution: expansions, properties and estimation}

The cdf and pdf in (6) and (7), respectively, can be expressed using similar algebra of Section 3. By replacing (8) in (3), the RBXII density becomes

$$
f(x)=c d s^{-c} x^{c-1}\left[1+\left(\frac{x}{s}\right)^{c}\right]^{-d-1} \sum_{k=0}^{\infty} b_{k}\left[1+\left(\frac{x}{s}\right)^{c}\right]^{-d(a+k-1)} .
$$

After some algebra, we obtain

$$
f(x)=\sum_{k=0}^{\infty} v_{k} g(x ; s,(a+k) d, c),
$$

where $v_{k}=\frac{b_{k}}{a+k}$ and $g(x ; s,(a+k) d, c)$ is the BXII density function with scale parameter $s$ and shape parameters $c$ and $(a+k) d$. Equation (22) reveals that the RBXII density is an infinite linear combination of BXII densities. It has similar form of equation (10) by changing $w_{r}$ by $v_{k}$. By integrating equation (22) gives

$$
F(x)=\sum_{r=0}^{\infty} v_{r} G(x ; s,(a+k) d, c) .
$$




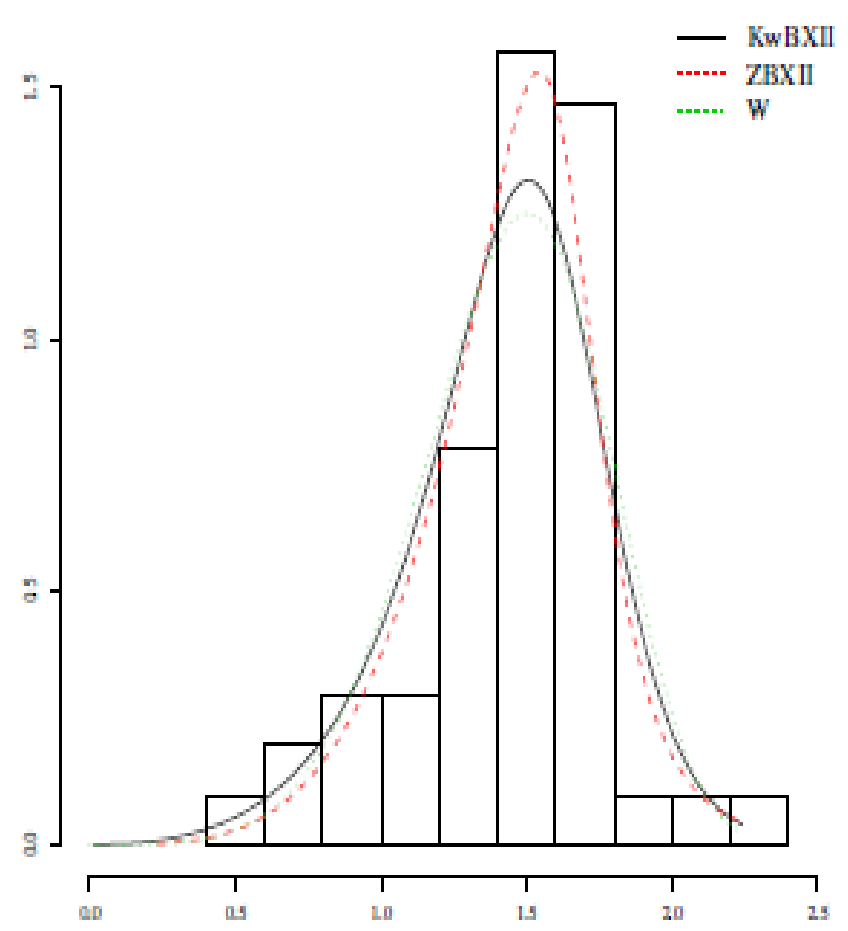

(a)

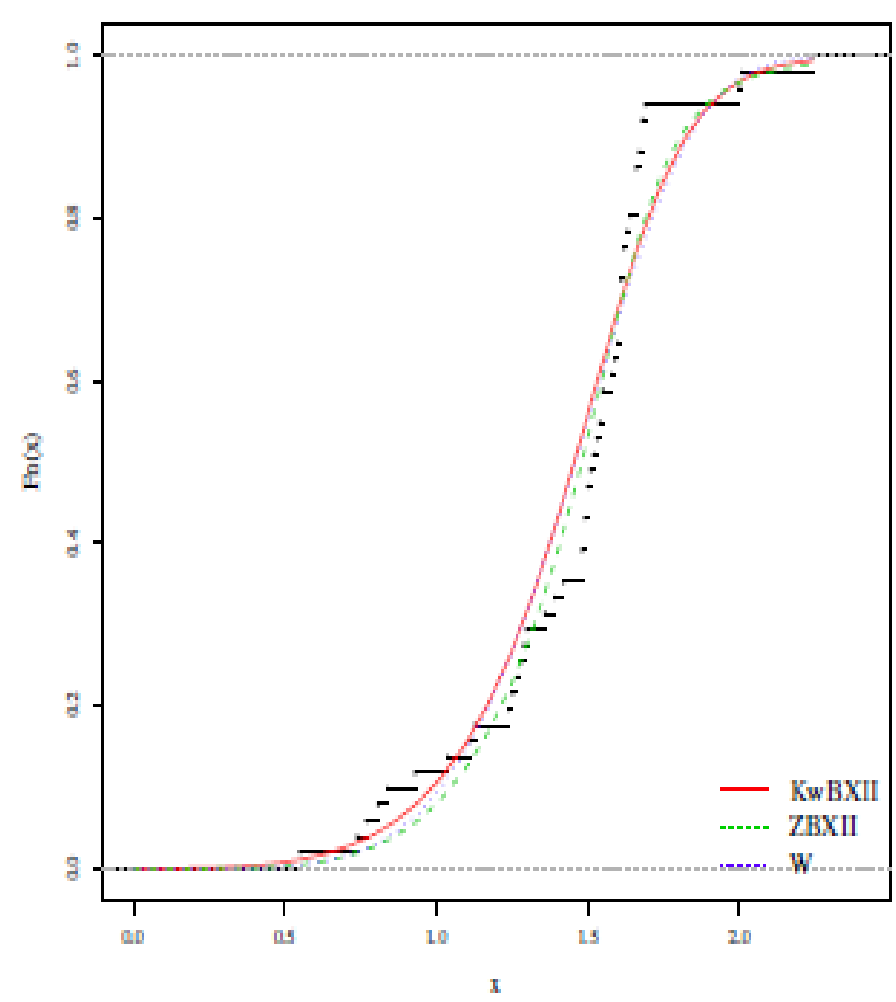

(b)

Figure 7: (a) Estimated densities of the BBXII, KwBXII and ZBXII models for fibres data; (b) estimated and empirical cumulative functions of these models for fibres data 
Table 7: The MLEs of the model parameters for fibres data and corresponding standard errors in parentheses.

\begin{tabular}{lccccc}
\hline & $\mathrm{c}$ & $\mathrm{d}$ & $\mathrm{s}$ & $\mathrm{a}$ & $\mathrm{b}$ \\
\hline BBXII & 7.5794 & 17.7507 & 1.9162 & 0.4901 & 0.2338 \\
& $(0.6201)$ & $(0.5416)$ & $(0.0989)$ & $(0.0739)$ & $(0.0916)$ \\
KwBXII & 7.4207 & 13.4946 & 1.7848 & 0.4871 & 0.2055 \\
& $(0.6451)$ & $(1.8976)$ & $(0.1892)$ & $(0.2535)$ & $(0.1088)$ \\
ZBXII & 18.6254 & 0.4571 & 1.6684 & 0.2548 & \\
& $(4.9883)$ & $(0.2370)$ & $(0.0545)$ & $(0.0870)$ & \\
BXII & 5.7354 & 7.6360 & 2.1966 & & \\
& $(0.8284)$ & $(7.4433)$ & $(0.4798)$ & & \\
& $\mathrm{c}$ & $\mathrm{m}$ & & & \\
LL & 7.5390 & 1.4570 & & & \\
& $(0.9255)$ & $(0.0456)$ & & & \\
EW & $\lambda$ & $\alpha$ & $\beta$ & & \\
W & 0.6204 & 5.8931 & 0.8255 & & \\
& $(0.0453)$ & $(1.5640)$ & $(0.3679)$ & & \\
\hline
\end{tabular}

Then, the ordinary moments (13), incomplete moments (14) and mgfs in (15) and (17) for the ZBXII distribution also hold for the RBXII distribution by changing $w_{r}$ by $v_{k}$.

The explicit expression for the qf of the RBXII distribution, say $Q(u)$, is

$$
Q(u)=s\left\{\left[1-\frac{1}{\exp \left(Q^{-1}(a, u)\right)}\right]^{-\frac{1}{d}}-1\right\}^{1 / c} .
$$

The median $M$ and other quantiles of the RBXII distribution follow from (23) by replacing appropriate values for $u$. Again, the mean deviations for the RBXII distribution are analogous to their in ZBXII distribution by replacing the expansion coefficients (see Section 6).

Let $y_{1}, \ldots, y_{n}$ be a random sample of size $\mathrm{n}$ from the $\operatorname{RBXII}(a, c, d, s)$ distribution. The $\log$-likelihood function for the parameter vector $\boldsymbol{\theta}_{*}=(a, c, d, s)^{T}$ is

$$
\begin{aligned}
l\left(\boldsymbol{\theta}_{*}\right) & =n \log \left[\frac{c d}{s \Gamma(a)}\right]+(c-1) c^{-1} \sum_{i=1}^{n} \log \left(u_{i}-1\right)-(d+1) \sum_{i=1}^{n} \log \left(u_{i}\right) \\
& +(a-1) \sum_{i=1}^{n} \log \left[-\log \left(1-u_{i}^{-d}\right)\right]
\end{aligned}
$$


Table 8: Goodness-of-fit statistics for the fitted models for fibres data.

\begin{tabular}{lccccccc}
\hline & AIC & CAIC & BIC & HQIC & $W^{*}$ & $A^{*}$ & KS \\
\hline BBXII & 34.8875 & 36.2208 & 44.5466 & 38.5785 & 0.2432 & 1.3957 & 0.1993 \\
KwBXII & 33.8071 & 35.1405 & 43.4662 & 37.4982 & 0.2523 & 1.4062 & 0.1804 \\
ZBXII & $\mathbf{2 8 . 0 7 8 5}$ & $\mathbf{2 8 . 9 4 8 1}$ & 35.8058 & $\mathbf{3 1 . 0 3 1 4}$ & $\mathbf{0 . 2 2 1 5}$ & $\mathbf{1 . 2 3 7 2}$ & $\mathbf{0 . 1 4 8 0}$ \\
BXII & 33.2107 & 33.7214 & 39.0062 & 35.4253 & 0.3231 & 1.7593 & 0.1768 \\
LL & 40.8169 & 41.0669 & 44.6805 & 42.2933 & 0.4928 & 2.6569 & 0.1871 \\
EW & 33.4823 & 33.9930 & 39.2778 & 35.6969 & 0.3001 & 1.6733 & 0.1680 \\
W & 31.4875 & 31.7375 & $\mathbf{3 5 . 3 5 1 1}$ & 32.9639 & 0.3136 & 1.7258 & 0.1747 \\
\hline
\end{tabular}

where $u_{i}=1+\left(\frac{y_{i}}{s}\right)^{c}$. The components of the score vector $\boldsymbol{U}(\boldsymbol{\theta})$ are given by

$$
\begin{aligned}
U_{a}\left(\boldsymbol{\theta}_{*}\right) & =-n \psi(a)+\sum_{i=1}^{n} \log \left[-\log \left(1-u_{i}^{d}\right)\right] \\
U_{c}\left(\boldsymbol{\theta}_{*}\right) & =\frac{n}{c}+\sum_{i=1}^{n} \log \left(u_{i}-1\right)-\frac{d+1}{c} \sum_{i=1}^{n} \frac{\left(u_{i}-1\right) \log \left(u_{i}-1\right)}{u_{i}} \\
& +\frac{(a-1) d}{c} \sum_{i=1}^{n} \frac{\left(u_{i}-1\right) u_{i}^{d-1} \log \left(u_{i}-1\right)}{\left(1-u_{i}^{d}\right) \log \left(1-u_{i}^{d}\right)}, \\
U_{d}\left(\boldsymbol{\theta}_{*}\right) & =\frac{n}{d}-\sum_{i=1}^{n} \log \left(u_{i}\right)-(a-1) \sum_{i=1}^{n} \frac{u_{i}^{d} \log \left(u_{i}\right)}{\left(1-u_{i}^{d}\right) \log \left(1-u_{i}^{d}\right)}, \\
\text { and } & \\
U_{s}\left(\boldsymbol{\theta}_{*}\right) & =\frac{-n c}{s}+\frac{c(d+1)}{s} \sum_{i=1}^{n} \frac{\left(u_{i}-1\right)}{u_{i}}+\frac{c d(a-1)}{s} \sum_{i=1}^{n} \frac{\left(u_{i}-1\right) u_{i}^{d-1}}{\left(1-u_{i}^{d}\right) \log \left(1-u_{i}^{d}\right)},
\end{aligned}
$$

where $\psi($.$) is the digamma function. Setting these expressions, \boldsymbol{U}(\boldsymbol{\theta})=\mathbf{0}$, and solving them simultaneously yields the MLEs of the unknown parameters for the RBXII distribution.

\section{Concluding remarks}

In this paper, we introduce a four-parameter distribution, called the Zografos-Balakrishnan Burr XII (ZBXII) distribution. Its hazard rate function allows decreasing, decreasing-increasingdecreasing and upside-down bathtub shapes and provides a Burr XII generalization that may be useful to still more complex situations. The new distribution may be an interesting alternative for modelling income distributions, among other applications. We obtain some properties of the ZBXII distribution, perform the estimation of the parameters by maximum likelihood and provide two applications to real data. We prove empirically that the ZBXII distribution yields a good adjustment for both data sets and that it can be used effectively to obtain better 
fits than other classical lifetime models. We also present some mathematical properties and expansions for the so-called Ristić-Balakrishnan Burr XII (RBXII) distribution. Since the RBXII distribution has a similar structure to that one of the ZBXII distribution, its structural properties follow analogously but with different weights in the linear representation.

\section{References}

Al-Hussaini, E. and Hussein, M. (2011). Estimation using censored data from exponentiated Burr type XII population. American Open Journal Statistics 1, 33-45.

Al-Saiari, A. Y., Baharith, L. A. and Mousa, S. A. (2014). Marshall-Olkin extended Burr type XII distribution. International Journal of Statistics and Probability 3, 78-84.

Alzaatreh, A. and Knight, K. (2013). On the gamma-half normal distribution and its applications. Journal of Modern Applied Statistical Methods 12, 103-119.

Alzaatreh, A., Famoye, F. and C., L. (2012). Gamma-Pareto distribution and its applications. Journal of Modern Applied Statistical Methods 11, 7894.

Alzaatreh, A., Famoye, F. and Lee, C. (2014a). The gamma-normal distribution: Properties and applications. Computational Statistics and Data Analysis 69, 67 - 80.

Alzaatreh, A., Ghosh, I. and Said, H. (2014b). On the gamma-logistic distribution. Journal of Modern Applied Statistical Methods 13, 55-70.

Andrews, D. F. and Herzberg, A. M. (1985). Data: A Collection of Problems from Many Fields for the Student and Research Worker. Springer Series in Statistics, New York.

Bourguignon, M., Lima, M. d. C. S., Leo, J., Nascimento, A. D. C., Pinho, L. G. B. and Cordeiro, G. M. (2015). A new generalized gamma distribution with applications. American Journal of Mathematical and Management Sciences 34, 309-342.

Brzeziski, M. (2013). Parametric modelling of income distribution in central and eastern Europe. Central European Journal of Economic Modelling and Econometrics 5, 207 - 230.

Brzeziski, M. (2014). Empirical modeling of the impact factor distribution. Journal of Informetrics 8, $362-368$.

Burr, I. W. (1942). Cumulative frequency functions. Annals of Mathematical Statistics 13, $215-232$.

Castellares, F. and Lemonte, A. (2016). On the gamma dual Weibull model. American Journal of Mathematical and Management Sciences 35, 124-132.

Castellares, F. and Lemonte, A. J. (2015). A new generalized Weibull distribution generated by gamma random variables. Journal of the Egyptian Mathematical Society 23, 382 - 390. 
Cooray, K. and Ananda, M. (2008). A generalization of the half-normal distribution with applications to lifetime data. Communication in Statistics - Theory and Methods 37, 13231337 .

Cordeiro, G. and Lemonte, A. (2011). The beta-Birnbaum Saunders distribution: An improved distribution for fatigue life modeling. Computational Statistics and Data Analysis 55, 1445-1461.

Cordeiro, G. M., Ortega, E. M. M. and Popovi, B. V. (2014). The gamma-linear failure rate distribution: theory and applications. Journal of Statistical Computation and Simulation 84, 2408-2426.

Cordeiro, G. M., Aristizabal, W. D., Suarez, D. M. and Lozano, S. (2015a). The gamma modified Weibull distribution. Chilean Journal of Statistics 6, 37-48.

Cordeiro, G. M., Lima, M. d. C. S., Cysneiros, A., Pascoa, M. A. R., Pescim, R. R. and Ortega, E. M. M. (2015b). An extended Birnbaum-Saunders distribution: Theory, estimation and applications. Communications in Statistics - Theory and Methods 45, 2268-2297.

Cordeiro, G. M., Ortega, E. M. and Popovic, B. V. (2015c). The gamma-Lomax distribution. Journal of Statistical Computation and Simulation 85, 305-319.

Flajolet, P. and Odlyzko, A. (1990). Singularity analysis of generating functions. SIAM Journal on discrete mathematics $3,216-240$.

Flajolet, P. and Sedgewick, R. (2009). Analytic combinatorics. Cambridge University press.

Gomes, A. E., da Silva, C. Q. and Cordeiro, G. M. (2015). Two extended burr models: Theory and practice. Communications in Statistics - Theory and Methods 44, 1706-1734.

Gradshteyn, I. S. and Ryzhik, I. M. (2000). Table of Integrals, Series and Products. Academic Press, San Diego.

Guo, Q. and Gao, L. (2012). Distribution of individual incomes in China between 1992 and 2009. Physica A 391, 5139-5145.

Henniger, C. and Schmitz, H. (1989). Size distributions of incomes and expenditures: Testing the parametric approach. Discussion Paper A-219, SFB 303, Universität Bonn, Germany.

Jäntti, M. and Jenkins, S. P. (2010). The impact of macroeconomic conditions on income inequality. The Journal of Economic Inequality 8, 221-240.

Jones, A. M., Lomas, J. and Nigel, R. (2014). Applying beta-type size distributions to healthcare cost regressions. Journal of Applied Econometrics 29, 649-670.

Kenney, J. and Keeping, E. (1962). Moving averages, 3 edn. NJ: Van Nostrand. 
Kumar, D. (2016). Ratio and inverse moments of Marshall-olkin extended Burr type XII distribution based on lower generalized order statistics. Journal of Data Science 14, 5366.

Lima, M. C. S., Cordeiro, G. M. and Ortega, E. M. M. . (2015). A new extension of the normal distribution. Journal of Data Science 13, 385-408.

Lima, M. d. C. S. (2015). Mathematical properties of some generalized gamma models. Doctoral thesis, Universidade Federal de Pernambuco.

Łukasiewicz, P., Karpio, K. and Orłowski, A. (2010). The models of personal incomes in usa. Acta Physica Polonica A 121, 82-85.

Majumder, A. and Chakravarty, S. R. (1990). Distribution of personal income: Development of a new model and its application to U.S. income data. Journal of Applied Econometrics, 5, 189196.

Marinho, P. R. D., Bourguignon, M. and Dias, C. R. B. (2016). AdequacyModel: Adequacy of Probabilistic Models and General Purpose Optimization. URL https://CRAN.Rproject.org/package=AdequacyModel, $\mathrm{r}$ package version 2.0.0.

McDonald, J. B. and Xu, Y. J. (1995). A generalization of the beta distribution with applications. journal of econometrics. Journal of Econometrics 66, 133- 152.

Moors, J. (1988). A quantile alternative for kurtosis. The Statistician 37, 25-32.

Moura Jr, N. and Ribeiro, M. (2009). Evidence for the Gompertz curve in the income distribution of Brazil 19782005. The European Physical Journal B 67, 101-120.

Mudholkar, G. and Srivastava, D. (1993). Exponentiated Weibull family for analyzing bathtub failure-rate data. IEEE Transactions on Reliability 42, 299-302.

Nascimento, A. D. C., Bourguignon, M., Zea, L. M., Santos-Neto, M., Silva, R. B. and Cordeiro, G. M. (2014). The gamma extended Weibull family of distributions. Journal of Statistical Theory and Applications 13, 1-16.

Oluyede, B. O., Huang, S. and Pararai, M. (2013). A new class of generalized dagum distribution with applications to income and lifetime data. Journal of Statistical and Econometric Methods 3, 125-151.

Ortega, E. M., Lemonte, A. J., Silva, G. O. and Cordeiro, G. M. (2015). New flexible models generated by gamma random variables for lifetime modeling. Journal of Applied Statistics 42, 2159-2179. 
Paranaíba, P. F., Ortega, E. M., Cordeiro, G. M. and Pescim, R. R. (2011). The beta Burr XII distribution with application to lifetime data. Computational Statistics and Data Analysis 55, 1118-1136.

Paranaíba, P. F., Ortega, E., Cordeiro, G. and Pascoa, M. A. R. (2013). The Kumaraswamy Burr XII distribution: Theory and practice. Journal of Statistical Computation and Simulation 83, 2117-2143.

Pareto, V. (1987). Cours d'conomie politique. Librairie de l'Université, Lausanne.

Percontini, A., Gomes-Silva, F., Ramos, M., Venancio, R. and Cordeiro, G. M. (2014). A distribuição gama Weibull Poisson aplicada a dados de sobrevivncia. TEMA 15, 165-176.

Pinho, L. G. B., Cordeiro, G. M. and Nobre, J. N. (2012). The gamma-exponentiated Weibull distribution. Journal of Statistical Theory and Applications 11, 379-395.

Press, W. H., Teukolsky, A. A., Vetterling, W. T. and Flanner Y, B. P. (2007). Numerical Recipes in C: The Art of Scientific Computing, 3 edn. Cambridge University Press, New York.

Prudnikov, A. P., Brychkov, Y. A. and Marichev, O. I. (1992). Integrals and Series, vol 4. Gordon and Breach Science Publishers, Amsterdam.

Prudnikov, P., Brychkov, A. and Marichev, O. I. (1986). Integrals and series: special functions, vol 2. CRC Press.

Ramos, M. W. A., Cordeiro, G. M., Marinho, P. R. D., Dias, C. R. B. and Hamedanim, G. G. (2013). The Zografos-Balakrishnan log-logistic distribution: Properties and applications. Journal of Statistical Theory and Applications 12, 225-244.

Ristić, M. and Balakrishnan, N. (2012). The gamma exponentiated exponential distribution. Journal of Statatistics Computation and Simulation 82, 1191-1206.

Shakeel, M., Hussain, I., Arif, M. M., Ameen, M. and Ahsan ul haq, M. (2015). Parametric modeling of household income distribution in the Punjab, Pakistan. Science International (Lahore) 27, 4161-4170.

Shao, Q. (2004). Notes on maximum likelihood estimation for the three-parameter Burr XII distribution. Computational Statistics and Data Analysis 45, 675-687.

Shao, Q., Wong, H. and Xia, J. (2004). Models for extremes using the extended three parameter Burr XII system with application to flood frequency analysis. Hydrological Sciences Journal des Sciences Hydrologiques 49, 685-702. 
Silva, G. O., Ortega, E. M. M., Garibay, V. C. and Barreto, M. L. (2008). Log-Burr XII regression models with censored data. Computational Statistics and Data Analysis 52, $3820-3842$.

Silva, R. V., Andrade, T. A. N., Maciel, R. P. S., Diego B. M. Campos and Cordeiro, G. M. (2013). A new lifetime model: The gamma extended Frechet distribution. Journal of Statistical Theory and Applications 12, 39-54.

Singh, S. K. and Maddala, G. S. (1975). A stochastic process for income distribution and tests for income distribution functions. Em: ASA Proceedings of the Business and Economic Statistics Section, pp. 551- 553.

Singh, S. K. and Maddala, G. S. (1976). A function for the size distribution of incomes. Econometrica 44, 963-970.

Smith, R. L. and Naylor, J. C. (1987). A comparison of maximum likelihood and bayesian estimators for the three-parameter Weibull distribution. Applied Statistics 36, 358-369.

Tanak, A. K., Borzadaran, G. M. and Ahmadi, J. (2015). Entropy maximization under the constraints on the generalized gini index and its application in modeling income distributions. Physica A 438, 657-666.

Torabi, H. and Hedesh, N. M. (2012). The gamma-uniform distribution and its applications. Kybernetika 48, 16-30.

Wu, S. J., Chen, Y. J. and T., C. C. (2007). Statistical inference based on progressively censored samples with random removals from the Burr type XII distribution. Journal of Statistical Computation and Simulation 77, 19-27.

Zimmer, W. J., Keats, J. B. and Wang, F. K. (1998). The Burr XII distribution in reliability analysis. Journal of Quality Technology 30, 386-394.

Zografos, K. and Balakrishnan, N. (2009). On families of beta- and generalized gammagenerated distributions and associated inference. Statistical Methodology 6, 344-362. 